\title{
The Impact of China 's Economic Growth on Carbon Emission Based on Gray Relational Analysis
}

\author{
Jianna Zhao \\ Department of Economics and Management, North China \\ Electric Power University, China \\ No.689 Huadian Road, Beishi district, Baoding, 071003, \\ China \\ zhjnzhf@163.com
}

\author{
Fengyi Zhao* \\ Department of Economics and Management, North China \\ Electric Power University, China \\ No.689 Huadian Road, Beishi district, Baoding, 071003, \\ China \\ 409764198@qq.com
}

\begin{abstract}
Economic and technological development is very fast in modern society, but economic development will affect the environmental change, which have a certain impact on carbon emissions at the same time. In the paper, the Gray Relational Analysis method is used to analyze and evaluate the correlation between China's economic growth and the carbon emissions of different industries in recent years. Therefore we can analyze to find out the pollution source of carbon emission that the growth of China's carbon emissions is mainly distributed in the transportation and industry to provide certain reference for China's economic development. Although it has made a great contribution to the economic growth of our country, it has also brought some degree of environmental pollution to our country. So we should pay attention to the energy conservation and emission reduction of these types of industries while raising the economy.
\end{abstract}

Keywords-Economic growth; Grey Relational Analysis; Transportation and Industry; Carbon emission

\section{INTRODUCTION}

Since the reform and opening-up policy, China's economy has developed rapidly. GDP rose from 93.9 billion dollars in 1978 to 8,260 billion dollars in 2012,and the total import and export increased from 20.6 billion dollars in 1978 to 3,866.8 billion dollars in 2012, which have increased 87 and 187 times respectively in 30 years. In particular, when China access to the WTO, China's GDP and import and export have maintained rapid growth, which has made important contributions to the economic development of our country. At the same time, China's environmental pollution is serious day by day, and energy consumption is increasing, therefore the carbon emissions as a result also continue to rise. According to the International Energy Agency's statistics, the average growth rate of carbon emissions from the combustion of fossil fuels from 1980 to 2008 was about 5.7\%. China's carbon emissions growth accounted for more than $50 \%$ of global carbon emissions growth, especially over the past year in 2007. Because of this reason, some scholars also put China's export trade as one of the "three engines" for domestic pollution emissions ${ }^{[1]}$. This is also a negative impact of our economic growth.
The impact of China's economic growth on carbon emissions can be seen as a complex gray system. We can use gray relational analysis to analyze and evaluate the correlation between China's economic growth and carbon emissions. It is helpful to find out the location of the key pollution sources of carbon emissions in China's economic growth. Take effective countermeasures to prevent the economic growth on the ecological environment ${ }^{[2]}$.

\section{Method(GRA)}

Gray Relational Analysis is a multi-factor statistical analysis method, which is based on the sample data of each factor and use correlation to describe the strength and magnitude of the relationship between factors and the order. Therefore the essence is to analyze and calculate the similar and dissimilarity of related sequences. The more consistent the development trend of the objects expressed by the sequence, the greater the degree of correlation is; on the contrary, the smaller the degree of association is. The sequence of the study can be either a time series or a spatial series. Gray Relational Analysis requires less data and less computation, which is easy to apply ${ }^{[3]}$

\section{A. Definition}

Set $X_{0}=\left(x_{0}(1), x_{0}(2) \ldots, x_{0}(n)\right)$ for the system feature sequence and Set $X_{1}=\left(x_{1}(1), x_{1}(2) \ldots, x_{1}(n)\right), X_{i}=$ $\left(x_{i}(1), x_{i}(2) \ldots, x_{i}(n)\right)$ and $X_{m}=\left(x_{m}(1), x_{m}(2) \ldots, x_{m}(n)\right)$ for sequence of related factors, then $\gamma_{0 i}=\frac{1}{n} \sum_{k=1}^{n} \gamma_{0 i}(k)=$ $\gamma_{0 i}\left(X_{0}, X_{i}\right)=\frac{1}{n} \sum_{k=1}^{n} \gamma_{0 i}\left(x_{0}(k), x_{i}(k)\right)$ is the gray relational degree between $X_{i}$ and $X_{0}$, and $\gamma_{0 i}\left(x_{0}(k), x_{i}(k)\right)$ is the correlation coefficient between $X_{i}$ and $X_{0}$ at k point.

The general association degree is divided into three categories according to the strength. That is to say, the weak association is from 0 to 0.35 , the middle association is from 0.35 to 0.7 , and the strong association is from 0.7 to $1^{[4]}$. 


\section{B. Calculation Steps}

1) Determination of reference sequence and comparison sequence

The data sequence reflecting the characteristics of the system's behavior is called the reference sequence. And data sequence that affects the behavior of the system is called comparison sequence.

\section{2) The initial value of each sequence}

Due to the different physical meaning of each factor in the system, the data may be different in dimension, which makes it inconvenient to compare data or is difficult to get the correct conclusion in comparison. Therefore, In general, we should conduct non-dimensional data processing while we apply gray relational analysis.

$$
\begin{aligned}
& \mathrm{X}_{\mathrm{i}}^{\prime}=\frac{\mathrm{x}_{\mathrm{i}}(\mathrm{k})}{\mathrm{x}_{\mathrm{i}}(1)}=\left(\mathrm{x}_{\mathrm{i}}^{\prime}(1), \mathrm{x}_{\mathrm{i}}^{\prime}(2), \mathrm{x}_{\mathrm{i}}^{\prime}(3) \ldots, \mathrm{x}_{\mathrm{i}}^{\prime}(\mathrm{n})\right), \\
& \mathrm{i}=0,1,2, \ldots, \mathrm{n} ; \mathrm{k}=1,2,3, \ldots, \mathrm{m} \\
& \text { 3) Inverse Sequence } \\
& \Delta_{i}(k)=\left|\mathrm{x}_{0}^{\prime}(\mathrm{k})-\mathrm{x}_{\mathrm{i}}^{\prime}(\mathrm{k})\right| \\
& \Delta_{i}=\left(\Delta_{i}(1), \Delta_{i}(2), \ldots, \Delta_{i}(n)\right) \\
& \mathrm{i}=1,2,3, \ldots, \mathrm{m}
\end{aligned}
$$

4) The maximum difference between the poles and the second smallest difference

$$
\mathrm{M}=\max _{\mathrm{i}}, \max _{\mathrm{k}} \Delta_{\mathrm{i}}(\mathrm{k}), \mathrm{m}=\min _{\mathrm{i}}, \min _{\mathrm{k}} \Delta_{\mathrm{i}}(\mathrm{k})
$$

5) Correlation coefficient.

In essence,the so-called degree of correlation is the degree of difference between the geometric shapes of the curves. Therefore, the size of the difference between the curves can be used as a measure of the degree of association. There are several comparison sequences $\left(\mathrm{X}_{1}, \mathrm{X}_{2} \ldots \mathrm{X}_{\mathrm{n}}\right)$ for a reference sequence $\mathrm{X}_{0}$. The correlation coefficient $\gamma_{0 i}(\mathrm{k})$ between each comparison series and the reference series at each moment, each point in the curve, can be calculated by the following formula.

We set $\delta$ as resolution coefficient, and $\delta$ generally from 0 to 1 , usually take 0.5 . Get $\mathrm{m}$ from above is the second smallest difference. And $\mathrm{M}$ is the maximum difference between the two levels. $\Delta_{i}(\mathrm{k})$ is the absolute difference between each point on the $\mathrm{Xi}$ curve of each comparison series and each point on the curve of the reference series.

$$
\begin{aligned}
& \gamma_{0 i}(k)=\frac{m+\delta M}{\Delta_{i}(k)+\delta M} \\
& \delta \epsilon(0,1), k=1,2,3, \ldots, n, i=1,2,3, \ldots m ; \delta=0.5
\end{aligned}
$$

6) The degree of correlation.

Because the correlation coefficient is the value of correlation degree, the points in the curve, between the comparison sequence and the reference sequence at each moment, it has more than one number, and the information is too scattered to compare with the whole set. Thus, it is necessary to focus on the correlation coefficient of each moment as a value, the average value, which is as a comparison between the number of columns and the number of reference series. The correlation degree formula is as follows:

$$
\gamma_{0 \mathrm{i}}=\frac{1}{\mathrm{n}} \sum_{\mathrm{k}=1}^{\mathrm{n}} \gamma_{0 \mathrm{i}}(\mathrm{k}) \mathrm{i}=1,2,3, \ldots, \mathrm{m}
$$

7) Ranking of relevance

The degree of association between factors is mainly described by the order of magnitude of relevance, and it is not just the degree of relevance. The order of relevance of $\mathrm{m}$ subsequences to the same parent sequence arrange in order of magnitude to constitute the associated order, denoted $\{x\}$, which reflects the "pros and cons" relationship of the subsequences for the parent sequence. If $\mathrm{y}_{0 \mathrm{i}}>\mathrm{y}_{0 \mathrm{j}},\left\{\mathrm{x}_{\mathrm{i}}\right\}$ is said to be better than $\left\{x_{j}\right\}$ for the same mother sequence, denoted by $\left\{\mathrm{x}_{\mathrm{i}}\right\}>\left\{\mathrm{x}_{\mathrm{j}}\right\}$ and $\mathrm{y}_{0 \mathrm{i}}$ represents the $\mathrm{i}$-th subsequence of the parent series eigenvalue.

Therefore, Gray Relational Analysis is a multi-factor statistical analysis method, which is based on the sample data of each factor, using gray relational degree to describe the strength and magnitude of the relationship between factors and the order, the essence is the similarity or correlation of related sequences Different degrees of analysis and calculation. The gray relational analysis method regards the value of the research object and the influencing factor as a point on the line, compares it with the curve drawn by the factor value of the object to be identified and the influencing factor., We can calculate the degree of closeness between the research object and each influencing factor of the object to be identified by comparing the closeness between them and quantifying them separately. Therefore we get a method to determine the object to be identified on the impact of the study object by comparing the size of the relevance.

\section{RESUlT(THE IMPACT OF CHINA 'S ECONOMIC GROWTH ON CARBON EMISSIONS BASED ON GRAY RELATIONAL ANALYSIS)}

\begin{tabular}{|c|c|c|c|c|}
\hline $\begin{array}{c}\text { Industry and } \\
\text { Year } \\
\end{array}$ & 2003 & 2004 & 2005 & 2006 \\
\hline $\begin{array}{l}\text { Total carbon } \\
\text { emissions }\left(X_{0}\right)\end{array}$ & 126323 & 146172.3 & 169086.4 & 186429.1 \\
\hline Industry $\left(X_{1}\right)$ & 94742.6 & 110155.5 & 121869 & 133586.1 \\
\hline $\begin{array}{c}\text { Farming } \\
\text { industry }\left(\mathbf{X}_{2}\right)\end{array}$ & 10196.1 & 12080.7 & 13283.8 & 14651.3 \\
\hline $\begin{array}{c}\text { Transportation } \\
\text { industry }\left(\mathrm{X}_{3}\right)\end{array}$ & 3578.7 & 4115.2 & 4385.1 & 4572.7 \\
\hline $\begin{array}{c}\text { Wholesale, } \\
\text { retail and } \\
\text { accommodation, } \\
\text { restaurants }\left(X_{4}\right)\end{array}$ & 2827.8 & 3238.9 & 3501.5 & 3838.3 \\
\hline $\begin{array}{l}\text { Construction } \\
\text { industry }\left(\mathrm{X}_{5}\right)\end{array}$ & 1965.1 & 2249.7 & 2458.2 & 2716.4 \\
\hline
\end{tabular}

A. Calculation of the Gray Relational Degree between the Total Amount of Carbon Emissions in China and the Amount of Carbon Emissions in Various Industries

Taking the carbon emissions of the five industries in China from 2003 to 2009 as sample data, we get the following table by sorting out the data of carbon emissions from 2003 to 2009:

TABLE I. CHINA'S TOTAL CARBON EMISSIONS FORM 2003 TO 2006 AND CARBON EMISSIONS IN FIVE MAJOR INDUSTRIES

Unit (million tons)

Source: China Energy Statistical Yearbook (calendar year) 
TABLE II. CHINA'S TOTAL CARBON EMISSIONS FROM 2007 TO 2009 AND CARBON EMISSIONS IN FIVE MAJOR INDUSTRIES

\begin{tabular}{|c|c|c|c|}
\hline & & & Unit (n \\
\hline $\begin{array}{c}\text { Industry and } \\
\text { Year }\end{array}$ & 2007 & 2008 & 2009 \\
\hline $\begin{array}{c}\text { Total carbon } \\
\text { emissions }\left(X_{0}\right)\end{array}$ & 203632.2 & 213324.2 & 211397.6 \\
\hline $\operatorname{Industry}\left(\mathrm{X}_{1}\right)$ & 144843.8 & 151178.9 & 158326.1 \\
\hline $\begin{array}{c}\text { Farming } \\
\text { industry }\left(\mathrm{X}_{2}\right)\end{array}$ & 15861.1 & 16553.2 & 17112.6 \\
\hline $\begin{array}{c}\text { Transportation } \\
\text { industry }\left(X_{3}\right)\end{array}$ & 4498.8 & 4343.3 & 4515.2 \\
\hline $\begin{array}{l}\text { Wholesale, retail } \\
\text { and } \\
\text { accommodation, } \\
\text { restaurants }\left(\mathrm{X}_{4}\right)\end{array}$ & 4109.4 & 4141.4 & 4631.6 \\
\hline $\begin{array}{l}\text { Construction } \\
\text { industry }\left(\mathrm{X}_{5}\right)\end{array}$ & 2981.3 & 2753.8 & 3295.1 \\
\hline
\end{tabular}

We can calculate the gray relational degree between carbon emissions and economic growth in China by taking the total carbon emissions in China from 2003 to 2009 as the sequence of characteristic behaviors and the carbon emissions of five major industries as the sequence of relevant factors.

1) The initial value of China's total carbon emissions from 2003 to 2009 and carbon emissions in five industries.

$\mathrm{X}_{0}^{\prime}=\left(\begin{array}{lllllll}1 & 1.1571 & 1.3385 & 1.4758 & 1.6120 & 1.6887 & 1.6735\end{array}\right)$

$\mathrm{X}_{1}^{\prime}=\left(\begin{array}{lllllll}1 & 1.1627 & 1.2863 & 1.4100 & 1.5288 & 1.5957 & 1.6711\end{array}\right)$

$\mathrm{X}_{2}^{\prime}=\left(\begin{array}{lllllll}1 & 1.1848 & 1.3028 & 1.4370 & 1.5556 & 1.6235 & 1.6783\end{array}\right)$

$X_{3}^{*}=\left(\begin{array}{lllllll}1 & 1.1499 & 1.2250 & 1.2778 & 1.2571 & 1.2137 & 1.2617\end{array}\right)$

$\mathrm{X}_{4}^{\prime}=\left(\begin{array}{lllllll}1 & 1.1454 & 1.2382 & 1.3573 & 1.4532 & 1.4645 & 1.6379\end{array}\right)$

$\mathrm{X}_{5}^{\prime}=\left(\begin{array}{lllllll}1 & 1.145 & 1.2509 & 1.3823 & 1.5171 & 1.4013 & 1.6768\end{array}\right)$

2) The Difference Sequence between the Total Carbon Emissions in China and the Initial Emissions of Carbon Emissions in Five Classes from 2003 to 2009.

$\Delta_{1}=\left(\begin{array}{lllllll}0 & 0.0056 & 0.0522 & 0.0658 & 0.0832 & 0.093 & 0.0024\end{array}\right)$

$\Delta_{2}=\left(\begin{array}{lllllll}0 & 0.0277 & 0.0357 & 0.0388 & 0.0564 & 0.0652 & 0.0048\end{array}\right)$

$\Delta_{3}=\left(\begin{array}{lllllll}0 & 0.0072 & 0.1135 & 0.198 & 0.3549 & 0.475 & 0.4118\end{array}\right)$

$\Delta_{4}=\left(\begin{array}{lllllll}0 & 0.0117 & 0.1003 & 0.1185 & 0.1588 & 0.2242 & 0.0356\end{array}\right)$

$\Delta_{5}=\left(\begin{array}{lllllll}0 & 0.0121 & 0.0876 & 0.0935 & 0.0949 & 0.2874 & 0.0033\end{array}\right)$

3) The difference between the two poles.

$\mathrm{M}=\max _{\mathrm{i}}, \max _{\mathrm{k}} \Delta_{\mathrm{i}}(\mathrm{k})=0.475, \mathrm{~m}=\min _{\mathrm{i}}, \min _{\mathrm{k}} \Delta_{\mathrm{i}}(\mathrm{k})=0$

4) The correlation coefficient $(\xi=0.5)$ between China's total carbon emissions from 2003 to 2009 and carbon emissions in five industries.

$$
\begin{aligned}
& \gamma_{01}(1)=1, \gamma_{01}(2)=0.9770, \gamma_{01}(3)=0.8198, \gamma_{01}(4)=0.7831, \\
& \gamma_{01}(5)=0.7406 \gamma_{01}(6)=0.7186, \gamma_{01}(7)=0.99 . \\
& \gamma_{02}(1)=1, \gamma_{02}(2)=0.8956, \gamma_{02}(3)=0.8693, \gamma_{02}(4)=0.8596, \\
& \gamma_{02}(5)=0.8081 \gamma_{02}(6)=0.7846, \gamma_{02}(7)=0.9802 .
\end{aligned}
$$

$$
\begin{aligned}
& \gamma_{03}(1)=1, \gamma_{03}(2)=0.9706, \gamma_{03}(3)=0.6766, \gamma_{03}(4)=0.5454, \\
& \gamma_{03}(5)=0.4009 \gamma_{03}(6)=0.3333, \gamma_{03}(7)=0.3658 . \\
& \gamma_{04}(1)=1, \gamma_{04}(2)=0.9534, \gamma_{04}(3)=0.7030, \gamma_{04}(4)=0.6671, \\
& \gamma_{04}(5)=0.5993 \gamma_{04}(6)=0.5144, \gamma_{04}(7)=0.8696 . \\
& \gamma_{05}(1)=1, \gamma_{05}(2)=0.9515, \gamma_{05}(3)=0.7305, \gamma_{05}(4)=0.7175, \\
& \gamma_{05}(5)=0.7145, \gamma_{05}(6)=0.4525, \gamma_{05}(7)=0.9863 .
\end{aligned}
$$

5) Gray Correlation Degree between China 's Total Carbon Emissions and Carbon Emissions in 5 Classes from 2003 to 2009.

$$
\gamma_{01}=0.8613, \gamma_{02}=0.8853, \gamma_{03}=0.6132, \gamma_{04}=0.7581 \text {, }
$$
$\gamma_{05}=0.6993$.

According to the order of the gray relational rankings, we get the right order: $\gamma_{02}>\gamma_{01}>\gamma_{04}>\gamma_{05}>\gamma_{03}$, which is transportation, industry, wholesale, retail and accommodation, catering industry, construction industry, agriculture, forestry, animal husbandry and fishery.

\section{B. Result Analysis}

We can get results from the above analysis, which is $\gamma_{02}>\gamma_{01}>\gamma_{04}>0.7>\gamma_{05}>\gamma_{03}>0.35$. That is to say, the carbon emissions of the catering, transportation, industrial, wholesale, retail and accommodation sectors and the economic growth in China are strongly associated (>0.7),and the carbon emissions of construction, agriculture, forestry, animal husbandry and fishery are moderately related to the economic growth of our country, which indicate that the impact of our country's economic growth on its carbon emissions is lower than the previous industries.

\section{SUMMARY}

It is inevitable that the growth of country's economy will lead to the continuous development of industrialization and continuous improvement of productivity. However, the resulting environmental pollution is an unavoidable fact that China faces the same problem in the fast-growing economy. The above data analysis shows that China's carbon emissions growth is mainly in the transport and industrial. Although it has made a great contribution to the economic growth of our country, it has also brought a certain degree of environmental pollution to our country. Therefore, our country should pay attention to the energy conservation and emission reduction of these types of industries while raising the economy. In contrast, carbon emissions of farming, forestry, animal husbandry and fishery industry are lower than other industries, its economic level is also lower than other industries. Therefore, our country should also promote the development of other industries while focusing on economic growth. In this way, our country can bring some benefits to our environment while economic growth.

\section{ACKNOWLEDGMENT}

This research was financially supported by the National Science Foundation. The authors thank professor Zhao for her 
valued assistance and guidance. The authors can learn a lot of professional knowledge to improve personal ability under the guidance of the professor. In addition, teacher educate study and life with her words and deeds.

\section{REFERENCES}

[1] Zhang Youguo. Energy and Environmental Costs of China's Trade Growth [J]. Quantitative and Technical Economics, 2009 (1): 16-30.

[2] Li Rashun, Zhao Jianna.China's export trade on the impact of the ecological environment by gray incidence analysis [J]. Ecological Economics, 2009 (5): 99-102.

[3] ZHAO Jian-na. Gray Relational Analysis of the Impact of China's Export Trade on Industrial Emissions [J] .Productivity Research, 2009 (20): 70-74.

[4] Xiao Li, Tan Zhongzhen, Liu Chunyang.Considering the Gray Relational Analysis of Hunan's Export Commodity Structure and Export Trade Growth [J] .Journal of Enterprise Economics, 2010 (10): 116-119.
[5] Li Ye, Qin Meng.Comprehensive Evaluation of Urbanization Level Based on Gray Correlation Analysis - A Case Study of Central China Urban Agglomeration [J]. Henan Science, 2013 (3): 388-393.

[6] WEI Jun.A Study on Investment Proposal for a Water Supply Project Based on Gray Correlation Degree [D]. Xi'an University of Architecture and Technology, 2015.

[7] Jiang Youyi. Research on Overseas Petroleum Transportation Risk Management System Based on Gray Correlation Analysis [D] .East East University of Science and Technology, 2011.

[8] Yu Xiao.Research on Marine Industrial Economy Based on Gray Correlation Analysis [J] .Mailline Development and Management, 2008, 25 (6): 76-79.

[9] Xie Songyun, Dong Daqun, Wang Benang.A Study on Target Recognition Based on Gray Relational Analysis [J] .Journal of System Simulation, 2002, 14 (2): 257-261.

[10] Gao Jinlong, Chen Jianglong, Xu Mengyue, et al.Research on the Development of Jiangsu Coastal Industries Based on Gray Relational Analysis [J]. Resources and Environment in the Yangtze Basin, 2012, 21 (7): 803. 